\title{
A laboratory-based approach to assess rockbolt behaviour in shear
}

\author{
G Snell University of Saskatchewan, Canada \\ E Kuley University of Saskatchewan, Canada \\ D Milne University of Saskatchewan, Canada
}

\begin{abstract}
Epoxy-bonded rebar is commonly used to support the roof of an underground potash mine. The rebar is often loaded in tension, but in certain circumstances, the potash can load the rebar in shear or by a combination of tension and shearing.

Rebar failure due to tension has been studied previously and is well understood. A laboratory test procedure has been developed to help quantify rebar shear behaviour. The rebar is tested by bonding it in three segments of steel pipe and applying a lateral load to the centre segment.

These tests isolate the rebar-epoxy interaction from the highly variable effect of the surrounding potash. The test method also allows for an easy and controlled comparison of different sizes of rebar, grades of rebar steel, and aperture between the pipe sections; all of which can significantly affect the behaviour of rebar in shear.

The data gathered during each test includes the load and displacement. However, distributed optical strain sensing is also being used, which allows for strain measurements at $0.5 \mathrm{~mm}$ resolution along the length of the rebar. This technology allows for detailed insight into rebar behaviour.

The International Minerals Innovation Institute (IMII), PotashCorp, The Mosaic Company, Agrium Inc., as well as Natural Sciences and Engineering Research Council of Canada (NSERC) are sponsoring this research project.
\end{abstract}

Keywords: potash, shear, rebar, fibre-optic

\section{Introduction}

Resin-grouted rebar bolts provide support for drift backs in potash mines, which can deform under a combination of shear and dilatational movement along clay seams. This research is being conducted to determine the response of fully bonded rebar bolts to combined shear and dilatational movements. The resistance to shear deformation of the bolt, provided by the adjacent rock mass, also influences the load on the installed support. This research consists of a laboratory component, a field testing component and a field monitoring component. This paper summarises the laboratory testing component of the research. The successful completion of this research will provide the mine engineer with guidelines to relate observed field deformations with loads on rebar support. These guidelines will assist in the design of an effective ground support program.

Many types of fully encapsulated rockbolts exist throughout the world. These types of rockbolts provide support to an underground opening through the interaction of three major components: a steel reinforcing $\mathrm{rod} / \mathrm{bar}$, a cementitious grout or a resin, and the surrounding rock mass. The steel provides the strength of the reinforcing system while the grout or resin bonds it to the surrounding rock mass.

Fully encapsulated rockbolts prevent failure of rock along discontinuities by resisting dilatational movement and shear movement of the rock. The support mechanism of rockbolts in pure tension has been studied significantly analytically, experimentally and numerically (Farmer 1975; Nemcik et al. 2014; Ghadimi et al. 2014; Neely 2014). 
The shear resistance of rockbolts has been studied to a lesser degree and for just reason. The interaction of the bolt, the grout or resin, and the surrounding rock is much more complex in shear movement along a discontinuity than for purely tensile movement. The shear contribution of rockbolts has been studied analytically by various researchers (Bjurstrom 1974; Stimpson 1987; Spang \& Egger 1990; Pellet \& Egger 1996) and has been studied through numerical modelling by others (Jalalifar et al. 2006). The specific results of past researchers are limited to the exact scenario they studied and extrapolation of their findings to other situations is difficult due to the large number of variables involved. These variables that could have an effect on the response of a bolt to shear deformation include:

- Area of bolt.

- Bending moment of inertia of bolt.

- Elastic modulus and yield/ultimate strength of the bolt.

- Size of drilled hole.

- Strength of grout/resin.

- Shear plane gap size.

- Dilatational movement of the shear plane.

- Angle of the bolt relative to the shear plane.

- Strength of the surrounding rock.

Many researchers have studied the effects of shear movement on rock support experimentally using concrete or excavated blocks of rock (Bjurstrom 1974; Spang \& Egger 1990; Aziz et al. 2003). A common experimental approach involved installing a fully encapsulated rockbolt across two or three blocks of concrete or rock. Loads are then applied to the blocks and they move in shear relative to one another. The load and corresponding displacement is measured.

The test procedure described is a valid test for many underground support applications. However, there are also several disadvantages:

- The testing apparatus must be spatially large and be capable of significant loads, often requiring a specialised testing apparatus.

- The tests can typically only be used to study 'tight' shear surfaces.

- To determine the rockbolts contribution to shear resistance, the friction on the shear surface of the concrete/rock must be identified and the normal stress applied to it must be measured during the test.

- Many researchers have had the concrete/rock blocks break or split during the tests which results in an invalid test.

- The shear resistance of the bolt is only valid for that specific strength of concrete/rock.

There is a clear need for refinement of the test or the creation of an entirely new testing method. In the hopes of creating a novel testing method, inspiration has been taken from tests conducted by researchers Dight (1982) and Dube (1995). The testing method that follows is not designed to replicate field conditions. It is designed to produce a standardised testing method that is capable of evaluating the effect that bolt type, grout and resin type, hole diameter, and shear plane gaps have on the bolt's response to shear deformation.

\section{$2 \quad$ Double shear pipe tests}

The new testing method described here involves installing bolts in three sections of pipe and applying a load to the centre pipe. Testing the rock support in steel pipe as opposed to concrete or rock is meant to simplify comparisons across the many different variables involved. 
The rockbolts are installed in schedule 160 steel pipe with an internal diameter matching the hole size of the field installation as close as possible. Schedule 160 steel pipe was chosen since it is thick walled, strong, and adequately stiff relative to the rockbolts to provide an unyielding confinement to the bolt system. Matching the internal diameter of the pipe to the diameter of the borehole will give an equivalent grout column to what is found in the field.

The outer sections of the steel pipe have three threaded holes to centre the bolt within it. The pipe is also temporarily attached to a larger section of pipe or angle iron to ensure the pipe sections are aligned. Figure 1 shows the installation set-up.

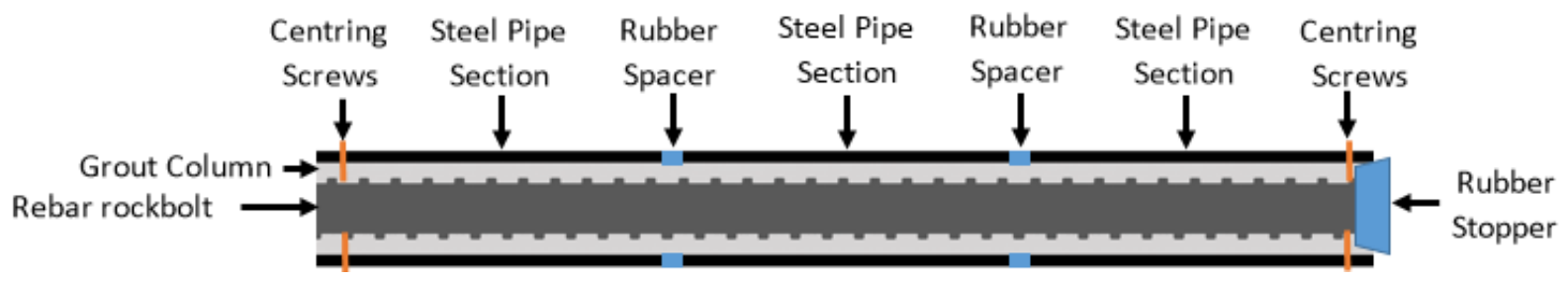

Figure 1 Installation of rockbolt in pipe sections

A pourable polyester resin grout was used for the tests. Strength tests on a similar grout have resulted in an unconfined compressive strength (UCS) of $80 \mathrm{MPa}$ and a Young's modulus of $8 \mathrm{GPa}$ for the grout. The grout used in the lab may not exactly match the grout cartridges used in the field, but the pourable grout is easily handled in the lab and can be mixed by hand to provide a consistent product. The testing specimens are given ample time for the grout to fully cure (minimum $24 \mathrm{hrs}$ ). The specimens are then set up to be tested.

Figure 2 shows an overview of the testing set-up. A loading frame applies an increasing load to the centre pipe segment through steel platens at the edges of the centre steel pipe. The outer two pipe segments are supported with bottom steel platens on the edge of the steel pipe segments. The outer pipe segments are clamped down near the ends of the specimen to minimise upward rotation of the outer pipe segments.

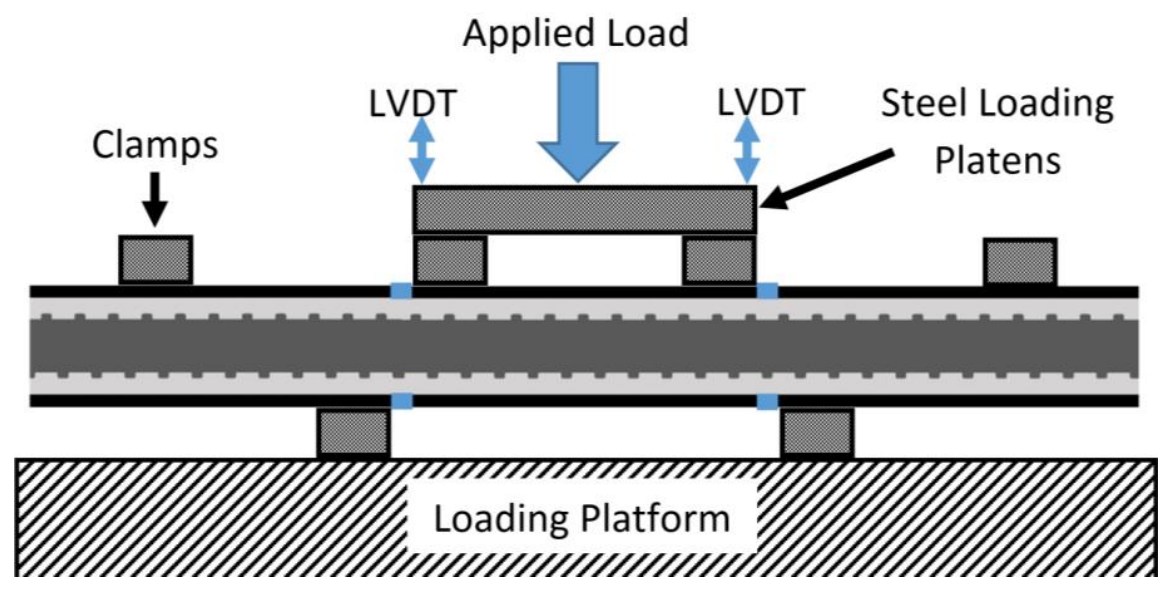

Figure 2 Double shear test set-up with measurement of the applied load and centre pipe displacement via linear variable differential transformers

During a test, the applied load and displacement of the centre pipe segment is continuously measured. Two linear variable differential transformers (LVDTs) measure the displacement as shown in Figure 2. Strain instrumentation could also be installed on the rebar to measure the strain in the rockbolt during testing.

\subsection{Testing program}

The testing program investigated the behaviour of \#8 rebar from Dywidag Systems International (DSI). This rebar is grade 60 steel, has a nominal diameter of $25 \mathrm{~mm}$, and has an average diameter of approximately $23.1 \mathrm{~mm}$. Laboratory tensile tests determined the rebar used has a yielding tensile strength of approximately $200 \mathrm{kN}$, an ultimate tensile strength (UTS) of approximately $310 \mathrm{kN}$, and a Young's modulus of $170 \mathrm{GPa}$. 
The rebar was installed in schedule 160 mild steel pipe with an internal diameter of $34.9 \mathrm{~mm}(1 \mathrm{3} / 8 \mathrm{in})$. Each segment is $406 \mathrm{~mm}$ (16 in) long. A two-part pourable polyester resin grout from DSI was used to bond the rebar in the pipe segments.

The variables investigated in this study were limited to the effect of the gap size on the behaviour of the rebar strength. The only researcher to consider this variable in the literature found was Stimpson (1987). Stimpson only considered a theoretical analysis of the effect of gap size on the stiffness of rebar with steel, grout, and rock behaving linear elastically. This study investigated the gap size by changing the thickness of the rubber spacers that separate the steel pipe segments. There were a total of seven samples tested with gap sizes ranging from 2 to $25 \mathrm{~mm}$.

A single sample was also tested using fibre-optic strain sensing. This method of strain sensing uses Rayleigh scattering of light waves to detect strain magnitudes at a resolution as small as $0.7 \mathrm{~mm}$ along the length of the optical fibre (Samiec 2012). The rebar rockbolt was instrumented with the optical fibre in three notches cut along the length of the bolt. The notch cuts are $3 \mathrm{~mm}$ wide and $3 \mathrm{~mm}$ deep. The fibre is epoxied into the notch and it is assumed that the strain in the fibre is equivalent to the strain in the rebar steel adjacent to the notch.

This method of strain sensing provides unique insight into the behaviour of the rebar. It can theoretically allow measurement of the exact time, position, load and displacement at which yielding of the steel starts. It also allows for the calculation of axial stress and the internal bending moment within the rebar.

\section{$3 \quad$ Results}

The seven double shear tests provided a large amount of data. All samples and tests performed as expected and the failed samples are shown in Figure 3. An issue immediately identifiable is the uneven loading of the two gaps. The applied load is theoretically divided equally between both gaps; however, this does not always hold true as six of the seven tests had one gap fail before the other. Additionally, the displacement occurring at each of the gaps is uneven. This could result in an underestimation of the ultimate load of the sample.

Figure 4 shows half of the load applied to the centre section of pipe plotted against the displacement of the centre section. The load is plotted as a percent of the UTS of $310 \mathrm{kN}$. The UTS of the fibre-optic instrumented sample has been corrected to $94 \%$ of $310 \mathrm{kN}$ to account for the reduced cross-sectional area. There is some erroneous data within the datasets that can be disregarded as instrumentation error.

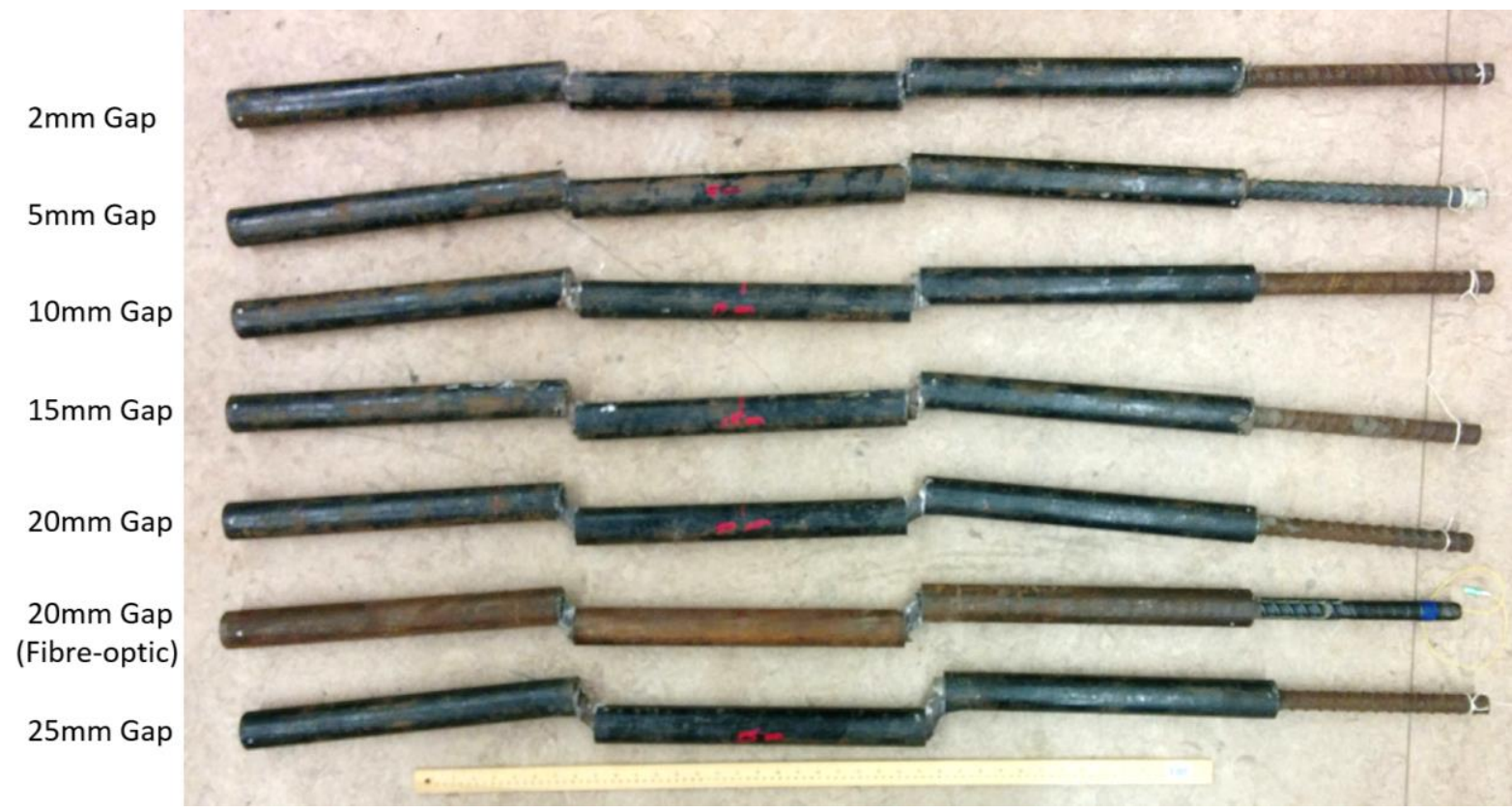

Figure 3 All samples after testing from $2 \mathrm{~mm}$ gap to $25 \mathrm{~mm}$ with a $1-\mathrm{m}$ stick for scale 


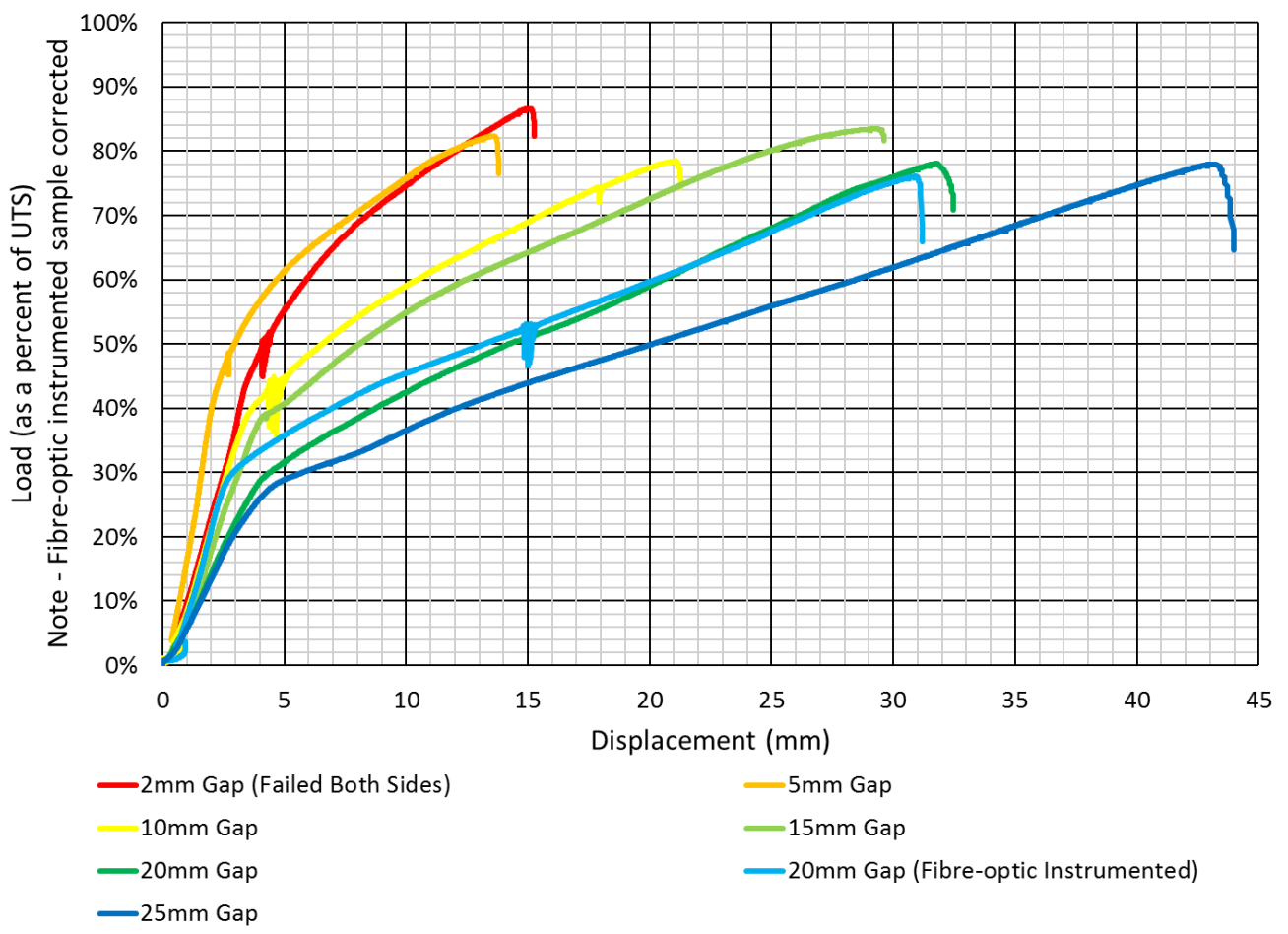

Figure 4 Load on each gap versus the average displacement of the centre pipe (rebar UTS is $310 \mathrm{kN}$ )

The load versus displacement plot shows the rebar is able to undergo more displacement prior to failure when the gap size is larger. Larger gap sizes also exhibit a lower stiffness as would be expected. Lastly, it should be noted that each test has an 'apparent yield point' beyond which the stiffness is significantly reduced. This yield point becomes more pronounced as the gap size increases, and less pronounced with a tighter gap.

Figure 5 shows the load at the observed yield point from Figure 4 plotted against the gap size of the samples. Figure 5 also plots the ultimate load recorded during testing.

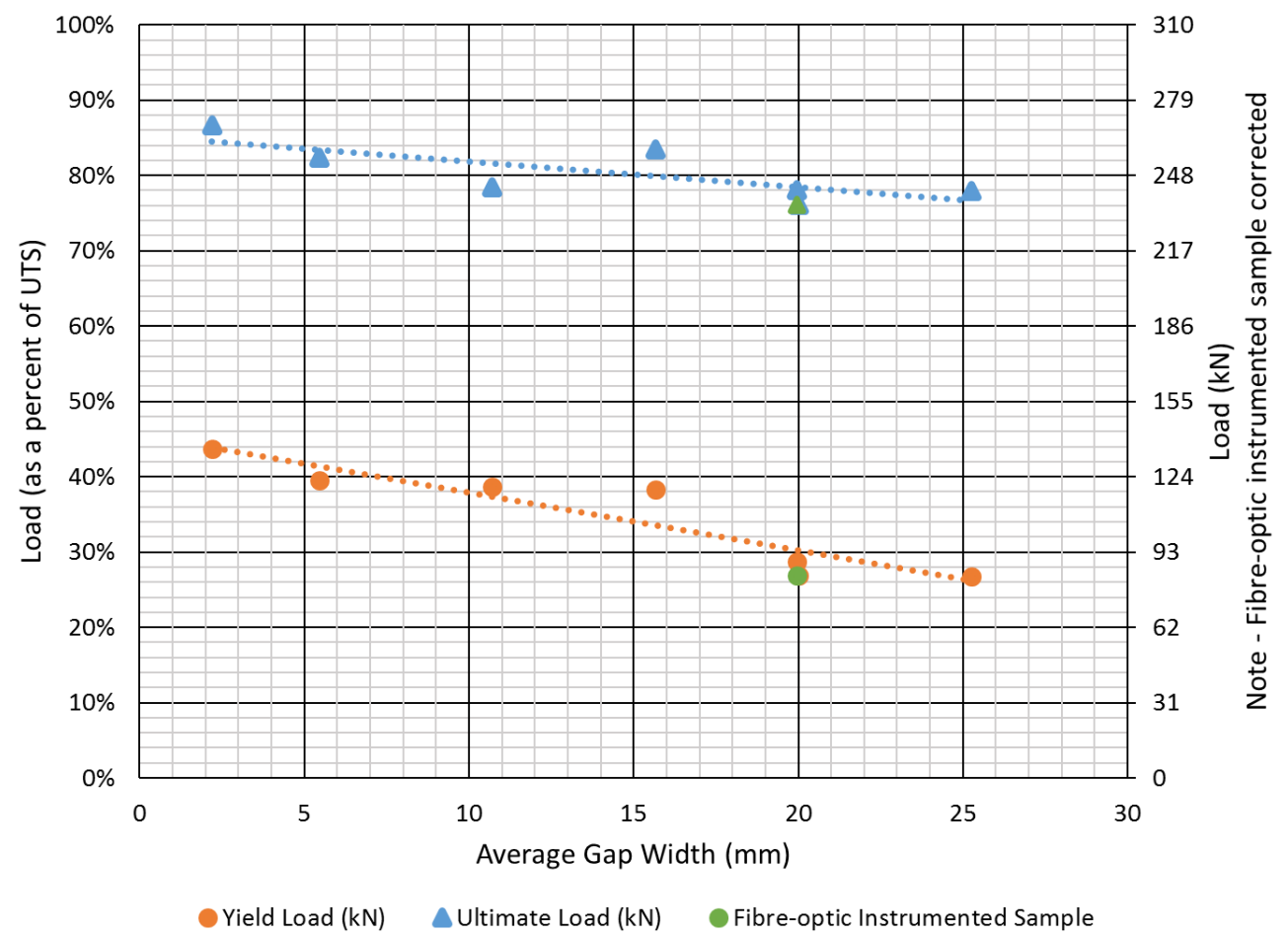

Figure 5 Load on each gap versus gap width 
Figure 5 shows that a decreasing load is required for the yield of the rebar as the gap width increases. This result is to be expected since a larger gap size suggests any force applied to the rebar will cause a larger bending moment. The ultimate load on the rebar presents an unexpected result; the ultimate load decreases slightly as the gap size increases. However, this decreasing trend is not as obvious. The decreasing load required to fail the rebar as gap size increases may correspond with uneven loading at the two gaps. Figure 6 shows the displacements measured by the two LVDTs at the ultimate load and the average of the values.

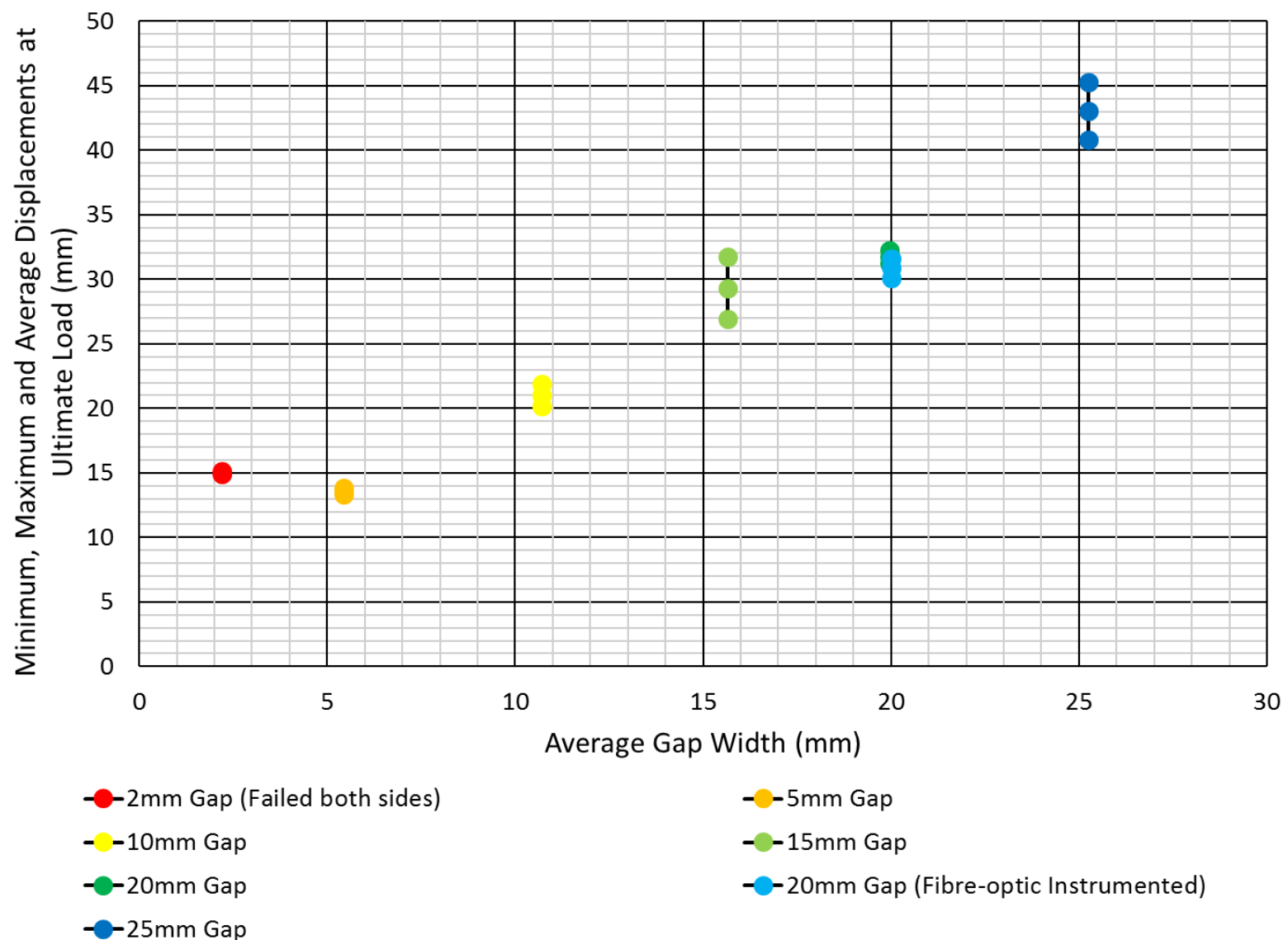

Figure 6 Minimum, maximum and average displacements measured at ultimate applied load

It is worth noting in Figure 5 that all samples showed an ultimate strength between 75 and $88 \%$ of their expected UTS. This strength is substantially higher than the $60 \%$ UTS value often assumed for shear loading conditions.

Figure 7 shows the displacement measured at the apparent yield and ultimate loads for each test. The average displacement at apparent yield load does not appear to change significantly with different gap widths. The displacement at ultimate load, however, changes considerably. The average displacement can increase significantly when a larger gap size is present. 




Figure 7 Average displacement of the centre pipe versus gap width

The one sample instrumented with fibre-optic strain sensing had a gap of approximately $20 \mathrm{~mm}$. The test resulted in an apparent yield load of $156 \mathrm{kN}$ and an ultimate load of $290 \mathrm{kN}$. The average displacements at these two loads were 2.44 and $30.9 \mathrm{~mm}$, respectively.

The fibre-optic strain results were used to find the axial strain within the rebar. Given the three-dimensional nature of the three fibre-optic strands along the rebar, the results were also used to mathematically resolve the strain at the top and the bottom of the rebar at each reading increment. The mathematical operations were simplified by assuming a linear vertical strain distribution within the rebar and by assuming the fibre-optic strands were 120 degrees apart.

The fibre-optic strain results for the apparent yield load of $156 \mathrm{kN}$, and corresponding displacement of $2.44 \mathrm{~mm}$, are shown in Figure 8. From this figure, the shear plane at each gap is visible as were the top and bottom strain switch between tensile and compressional. 


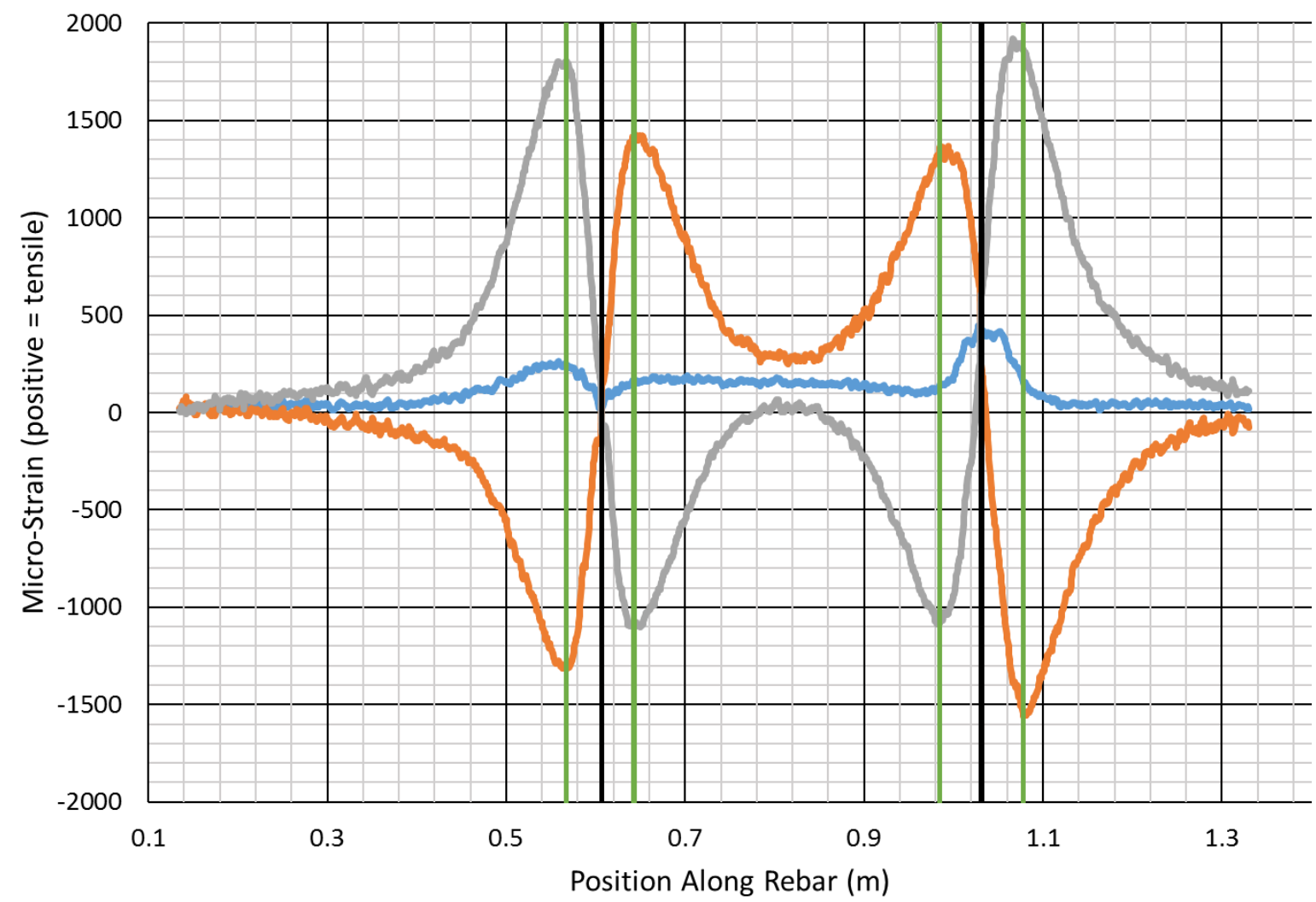

- Axial Strain — Bottom Strain — Top Strain —Inflection Points —Maximum Bending Moments

Figure 8 Rebar strain calculated from fibre-optic strain measurements

The points along the length of the rebar at which the curvature of bending switches is indicated by a reversal of the top and bottom strains. There are two of these points, called inflection points, in the rebar; one at each shear plane or gap. The exact positions of the inflections points from the fibre-optic data are 0.607 and $1.031 \mathrm{~m}$ from one end of the test section. These positions are $0.424 \mathrm{~m}$ apart. The centre pipe is known to be $0.406 \mathrm{~m}$ long and there is a $20 \mathrm{~mm}$ gap on each side. The theoretical inflection points should be approximately $0.426 \mathrm{~m}$ apart which is remarkably close to the $0.424 \mathrm{~m}$ measurement by the fibre-optic.

The fibre-optic strain data can be used to determine the positions of the maximum internal bending moment within the rebar; this is identifiable by the local maximums and minimums of the bottom and top strain in Figure 8. The positions calculated for the apparent yield load are presented in Table 1, as measured from the nearest inflection point. These positions of maximum bending moment are well within the pipe segments and not in the gap. This is of interest, since no samples were observed to break within the pipe segments. Some researchers have proposed rebar in shear will fail at the point of maximum bending moment. However, these findings disagree with such assumptions.

Table 1 Position of maximum internal bending moment from fibre-optic strain measurements

\begin{tabular}{ll}
\hline $\begin{array}{l}\text { Maximum internal bending moment } \\
\text { (numbered from left to right) }\end{array}$ & $\begin{array}{l}\text { Distance from nearest } \\
\text { inflection point }(\mathbf{m m})\end{array}$ \\
\hline 1 & 39.4 \\
2 & 36.3 \\
3 & 46.1 \\
4 & 47.3 \\
\hline
\end{tabular}


The maximum strain at the apparent yield load of $156 \mathrm{kN}$ is approximately 1,800 micro-strain. This is slightly lower than the experimentally gathered yield strain of 2,200 micro-strain. However, the fibre-optic strain sensor measured 2,200 micro-strain at approximately $165 \mathrm{kN}$. The difference in values are assumed to be insignificant and the apparent yield loads estimated from Figure 4 will be taken as an accurate representation of the yield point of steel.

The presence of tensile strain around position $0.8 \mathrm{~m}$ (Figure 8 ) is of note as this position is the middle of the centre pipe segment and indicates there is strain within the rebar. The pipe lengths of $406 \mathrm{~mm}$ were specifically chosen to be long enough to isolate the two gaps and securely anchor the rebar within the pipe. The presence of strain in this centre segment suggests there is communication of force between the two gaps. This strain, about 200 micro-strain, is relatively small and will not likely affect the test results, but should be noted.

\section{Conclusion}

The double shear experiment described herein is meant to address the need for a practical and standardised way to evaluate the performance of fully encapsulated rockbolts under shear or laterally loaded conditions. The test attempts to simplify the evaluation by removing the variables introduced by the variable conditions of rock or concrete. By isolating the variables, results will ideally have less variability and all testing can be performed by a common loading frame with regular clearances and load capacities.

The effect of gap size has been investigated in this study. The gap size has a notable effect on the stiffness of the rebar when loaded in shear. It also appears to reduce the yield and ultimate strength of the rebar, although this is only a limited effect and will be assessed more closely with further tests using fibre-optic instrumentation. Most significantly, the gap size has a large effect on the ultimate displacement that can occur in shear movement. This is valuable insight for any mining operation that approximate the failure of rockbolts in shear based upon the magnitude of the displacement.

Distributed fibre-optic strain sensing technology was also used in this study. This technology allows for a unique glimpse into the strain exhibited along the entire length of the rebar. Although this technology is not required for the double shear testing method, it provides supplementary information that can be of use. It is also expected to be useful in proving the efficacy of the double shear test.

More tests will be performed using the fibre-optic technology. Additionally, other bolt types will be evaluated using the double shear test and fibre-optic technology. This testing will serve to supplement field research being performed to evaluate the performance of fully encapsulated rebar in shear at Saskatchewan potash mines.

\section{Acknowledgement}

The authors thank the International Minerals Innovation Institute, PotashCorp, The Mosaic Company, Agrium Inc., NSERC, and Dywidag Systems International for technical and financial support.

\section{References}

Aziz, N, Pratt, D \& Williams, R 2003, 'Double shear testing of bolts', Proceedings of Coal 2003: Coal Operators' Conference, University of Wollongong, Wollongong, and Australasian Institute of Mining and Metallurgy, Melbourne, pp. 154-161.

Bjurstrom, S 1974, 'Shear strength of hard rock joints reinforced by grouted untensioned bolts', Proceedings of the 3rd International Conference of the International Society for Rock Mechanics, International Society for Rock Mechanics, Lisbon, pp. 1194-1200.

Dight, P 1982, Improvements to the Stability of Rock Walls in Open Pit Mines, PhD thesis, Monash University, Melbourne.

Dube, S 1995, A Laboratory Study on the Behaviour of Cable Bolts Subjected to Combined Tensile and Shear Loads, MSc thesis, Queen's University, Kingston.

Farmer, I 1975, 'Stress distribution along a resin grouted rock anchor', International Journal of Rock Mechanics and Mining Sciences and Geomechanics, vol. 12, pp. 347-351.

Ghadimi, M, Shahriar, K \& Jalalifar, H 2014, 'Analysis profile of the fully grouted rock bolt in jointed rock using analytical and numerical methods', International Journal of Mining Science and Technology, vol.4, no. 5, pp. 609-615.

Jalalifar, H, Aziz, N \& Hadi, M 2006, 'The effect of surface profile, rock strength and pretension load on bending behaviour of fully grouted bolts', Geotechnical and Geological Engineering, vol. 24, no. 5, pp. 1203-1227. 
Neely, D 2014, Failure Mechanism of Resin Anchored Rebar in Potash, MSc thesis, University of Saskatchewan, Saskatoon.

Nemcik, J, Ma, S, Aziz, N, Ren, T \& Geng, X 2014, 'Numerical modelling of failure propagation in fully grouted rock bolts subjected to tensile load', International Journal of Rock Mechanics \& Mining Sciences, vol. 71, pp. 293-300.

Pellet, F \& Egger, P 1996, 'Analytical model for the mechanical behaviour of bolted rock joints subjected to shearing', Rock Mechanics and Rock Engineering, vol. 29, no. 2, pp. 73-97.

Samiec, D 2012, 'Distributed fibre-optic temperature and strain measurement with extremely high spatial resolution', Optical Metrology Photonik International, pp. 10-13.

Spang, K \& Egger, P 1990, 'Action of fully-grouted bolts in jointed rock and factors of influence', Rock Mechanics and Rock Engineering, vol. 23, no. 3, pp. 201-229.

Stimpson, B 1987, 'An analytical method for determining shear stiffness of an inclined grouted bolt installed across an open discontinuity', International Journal of Mining and Geological Engineering, vol. 5, no. 3, pp. 299-305. 